\title{
FOLLOW-UP STUDIES OF RENAL FUNCTION IN PATIENTS WITH SPINAL CORD INJURIES OF TRAUMATIC ORIGIN
}

\author{
By MARY Price, M.D. \\ Department of Physical Medicine and Rehabilitation, \\ University of Minnesota Hospitals
}

RESULTS of the first four years of a Io-year programme to study changes in renal function in patients with spinal cord injury strongly suggest that if patients consistently adhere to a meticulous programme of self care so as to avoid infection and decubiti, glomerular, tubular and circulatory function of the kidney need not decline significantly over a period of sixteen years.

In 1963 letters to I I 5 patients with spinal cord injury, most of whom had been treated at the University of Minnesota Hospitals during the previous I 5 years, and personal communication with patients in hospital, resulted in urinary tract evaluation of 56 patients, together with nine normal controls. Criteria for study of these patients were that the injury to the spinal cord be traumatic in nature and that there be no concurrent systemic disease such as diabetes, tumor or residua of poliomyelitis.

\section{METHOD}

Glomerular filtration rate (GFR), renal plasma flow (RPF), and maximal tubular excretory capacity (TmPAH) were estimated using inulin and sodium hippurate as testing agents. The Bojeson (1952) method was utilised for inulin determination and the Smith modification of the Bratton-Marshal (1939) method was used for determination of sodium hippurate. These analyses were done in the renal function laboratory $\mathrm{c} f$ the Department of Physical Medicine and Rehabilitation, University of Minnesota.

Quality control of the chemical determinations consisted in the running of standards with each set of determinations as well as the recovery of known amounts of test substances added to the patients' plasma.

Prior to injection of testing agents, blood was drawn for determinations of complete blood count, fasting glucose, blood urea nitrogen, serum creatinine and total serum protein with electrophoretic pattern. These determinations were made in the diagnostic laboratories of the University of Minnesota Hospitals. Blood was also drawn for inulin and PAH blanks. Specimens for urinalysis and urine culture were obtained either the day previous or immediately before testing. After urine for culture had been obtained, Furadantin, $50 \mathrm{mg}$., every six hours, for five days, was given as a prophylactic medication. It had previously been determined that the presence of Furadantin would not influence the colorimetric method used. An indwelling urethral catheter was installed.

In order to determine RPF and GFR a priming dose of PAH $(4 \mathrm{mg}$. $/ \mathrm{Kg}$. body weight) and inulin $50 \mathrm{mg}$. $/ \mathrm{Kg}$. body weight) was injected intravenously. This was followed by a sustaining infusion of PAH at Io $\mathrm{mg} . / \mathrm{M}^{2}$ body surface/ minute and inulin (18.8 mg. $/ \mathrm{M}^{2}$ body surface/minute) in order to maintain blood levels of PAH between 2-4 mg. per cent. and inulin between $20-40 \mathrm{mg}$. per cent. A 
constant rate, variable speed injection pump was used. After an equilibration period of 45 minutes, urine specimens were collected every 20 minutes for three periods. This was done by draining the bladder and flushing with $20 \mathrm{ml}$. increments of sterile normal saline at $37^{\circ} \mathrm{C}$. until the return was clear. Two $20 \mathrm{ml}$. increments of air were injected to insure complete emptying of the bladder. About mid-way in each period blood specimens were drawn. Accurate notations of time intervals were made.

Following the third sample collections, a priming dose of $150 \mathrm{mg}$. $\mathrm{PAH} / \mathrm{Kg}$. body weight was injected at a rate of $\mathrm{I} .05 \mathrm{~g}$./minute in order to determine the TmPAH. This was followed by a sustaining solution of $70 \mathrm{mg}$. $\mathrm{PAH} / \mathrm{M}^{2} /$ minute and $\mathrm{I} 8.8 \mathrm{mg}$. inulin $\mathrm{M}^{2} /$ minute to maintain blood levels of $\mathrm{PAH}$ between $40-60 \mathrm{mg}$. per cent. and of inulin between $20-40 \mathrm{mg}$. per cent. Following a 45-minute equilibration period three more sets of urine and blood specimens were obtained as previously described. Blood pressure readings were recorded before testing, after each urine collection, and following administration of the TmPAH priming dose.

The inulin and para aminohippurate clearances were usually done in the morning and early afternoon. After giving the patient a back rub, lunch, and a few minutes of relaxation an excretory cystometrogram was made. On the following day an intravenous pyelogram and a voiding cystourethrogram were obtained.

Prior to study of patients, clearances on nine normal controls indicated that determinations made in our laboratory correlated closely with the normal values established by Homer Smith (1962). Values are given as milliliters or milligrams per square meter body surface per minute (Table I).

Marked depression of renal function is defined as the finding of values of more than two standard deviations below normal in two or more functions studied, i.e., in GFR, RPF, TmPAH. Moderate depression is defined as the finding of values which are two or more standard deviations below normal in one function.

\section{RESULTS}

During the first year of the study 56 patients with spinal cord injuries of from one month to I5 years' duration were evaluated. Half of these patients were paraplegic, half quadriplegic. The findings of this initial study indicated that in the patients who avoided recurrent infection and decubiti, renal function did not decline significantly over a period of fifteen years (Table I).

Only three patients had markedly depressed function (Table II). With the patient tabulated as 'Paraplegic I' it was possible to do a second study. The incredibly low values of GFR $6 \cdot \mathrm{I} \mathrm{ml} . / \mathrm{M}^{2} /$ minute, RPF $7 \cdot 7 \mathrm{ml} . / \mathrm{M}^{2} /$ minute and TmPAH $0.5 \mathrm{mg} . / \mathrm{M}^{2} /$ minute were found. Shortly after this the young man contracted pneumonia and died in renal failure. All three of these young men had had frequent severe infections and multiple decubiti. Follow-up findings on the two living patients with poor function are included in the following discussion.

There are now seventy two patients in this series. Twenty patients have had repeat studies. The evaluation of 26 patients in the first half of 1967 tends to confirm the indications of our previous reports (Price et al., I966, Price et al., in press).

In this series one paraplegic and four quadriplegic patients had spinal cord lesions of less than one year's duration. Eight paraplegic and four quadriplegic 
patients had sustained lesions between one and five years previously. Two paraplegic and seven quadriplegic patients had lesions of five to sixteen years' duration.

Inulin clearances indicate that mean values for glomerular filtration rates fell well within normal range. PAH clearance and TmPAH showed that renal plasma

TABLE I

Values for Renal Function Tests, 1963-64

\begin{tabular}{|c|c|c|c|c|}
\hline & No. & GFR & TmPAH & $\mathrm{RPF}$ \\
\hline Normal Values (Smith) & & $7 I \cdot 4 \pm I 4 \cdot 4$ & $45 \cdot 9 \pm 9 \cdot 7$ & $378 \cdot 0 \pm 94 \cdot 3$ \\
\hline \multicolumn{5}{|l|}{ Normal Control } \\
\hline 20-29 years & 5 & $64 \cdot 6 \pm 8 \cdot I$ & $40 \cdot 7 \pm 5 \cdot 3$ & $380 \cdot 2 \pm 4 I \cdot I$ \\
\hline $30-50$ years & 4 & $62 \cdot 0 \pm 10 \cdot 1$ & $41 \cdot 3 \pm 3 \cdot 8$ & $364 \cdot 6 \pm 65 \cdot I$ \\
\hline \multicolumn{5}{|l|}{ Lesions, O-I I months } \\
\hline Paraplegics & IO & $58 \cdot 3 \pm I I \cdot I$ & $43 \cdot 9 \pm 7 \cdot 6$ & $356 \cdot 5 \pm 107 \cdot 5$ \\
\hline Quadriplegics & 8 & $58 \cdot 8 \pm 12 \cdot 3$ & $45 \cdot 3 \pm 7 \cdot 6$ & $419 \cdot 6 \pm 113 \cdot 3$ \\
\hline \multicolumn{5}{|l|}{ Lesions, I-4 years } \\
\hline Paraplegics & 7 & $65 \cdot 8 \pm \mathrm{I} 4 \cdot \mathrm{I}$ & $44 \cdot 3 \pm 9 \cdot 3$ & $417 \cdot 3 \pm \operatorname{II} 2 \cdot 9$ \\
\hline Quadriplegics & Iо & $58 \cdot 6 \pm 10 \cdot 7$ & $43 \cdot 6 \pm 7 \cdot 4$ & $347 \cdot 9 \pm 75 \cdot 9$ \\
\hline \multicolumn{5}{|l|}{ Lesions, 5-16 years } \\
\hline Paraplegics & II & $57 \cdot 6 \pm 28 \cdot 2$ & $42 \cdot 9 \pm 16 \cdot 9$ & $424 \cdot 7 \pm 197 \cdot 5$ \\
\hline Quadriplegics & IO & $56 \cdot 3 \pm 13 \cdot 3$ & $37 \cdot 2 \pm 10 \cdot 3$ & $302 \cdot 5 \pm 54 \cdot 4$ \\
\hline
\end{tabular}

$\mathrm{GFR}=$ glomerular filtration rate $\mathrm{ml} . / \mathrm{M}^{2} /$ minute \pm I S.D.; $\mathrm{TmPAH}=$ tubular maximal excretory capacity $\mathrm{mg}$. $/ \mathrm{M}^{2} /$ minute; $\mathrm{RPF}=$ renal plasma flow $\mathrm{ml} . / \mathrm{M}^{2} /$ minute. Standard deviation is given for each value.

\section{TABLE II}

Values for Renal Function in Three Patients

With Severe Renal Involvement

$\begin{array}{lccc} & \begin{array}{c}\mathrm{GER} \\ \mathrm{ml} . / \mathrm{M}^{2} / \mathrm{min} .\end{array} & \begin{array}{c}\mathrm{TmPAH} \\ \mathrm{mg} \cdot / \mathrm{M}^{2} / \mathrm{min} .\end{array} & \begin{array}{c}\mathrm{RPF} \\ \mathrm{ml} . / \mathrm{M}^{2} / \mathrm{min} .\end{array} \\ \text { Normal values } & 7 \mathrm{I} \cdot 4 \pm \mathrm{I} 4 \cdot 4 & 45 \cdot 9 \pm 9 \cdot 7 & 378 \cdot 0 \pm 94 \cdot 3 \\ \text { Paraplegic I } & \mathrm{I} 7 \cdot 0 & 6 \cdot 0 & 49 \cdot 8 \\ \text { Quadriplegic I } & 28 \cdot 0 & 20 \cdot 4 & 249 \cdot 5 \\ \text { Quadriplegic II } & 42 \cdot 4 & 25 \cdot 8 & 255 \cdot 5\end{array}$

$\mathrm{GFR}=$ glomerular filtration rate; $\mathrm{TmPAH}=$ tubular maximal excretory capacity; $\mathrm{RPF}=$ renal plasma flow. Standard deviations are given.

flow and maximal tubular excretory capacities also remained within normal range (figs. I, 2 and 3 ).

Since mean values, particularly in small series, can be misleading, the serial findings in twenty patients are represented in Figures 4, 5 and 6. Study of the graphs will suggest that there may be a gradual decline in tubular function over a period of time. Statistical analysis has been carried out regarding rate of change in GFR, RPF, and TmPAH. Since time interval has been so short, the results of these analyses are not presented. 


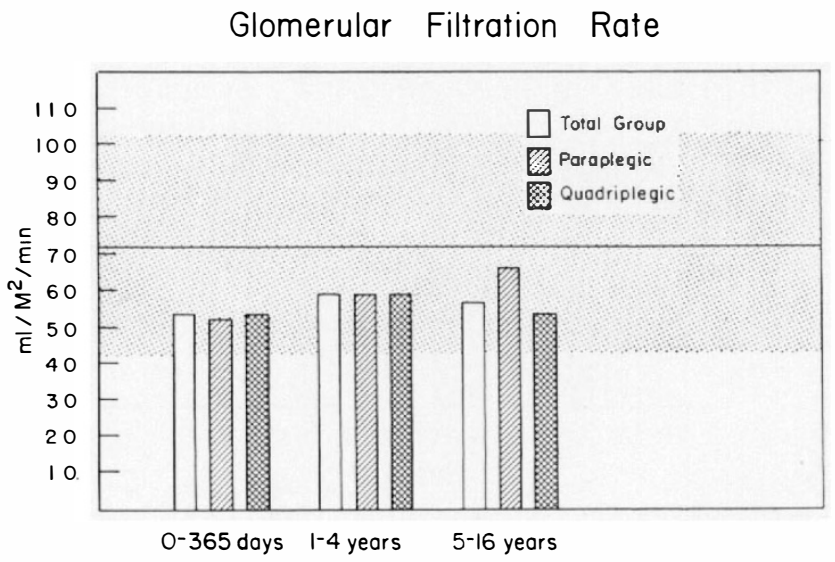

FIG. I

Mean values for glomerular filtration rates in patients with duration of lesion of 0-364 days, one through four years and five through sixteen years. Horizontal line indicates mean normal value. Cross hatching indicates two standard deviations above and below normal.

\section{TM-PAH}

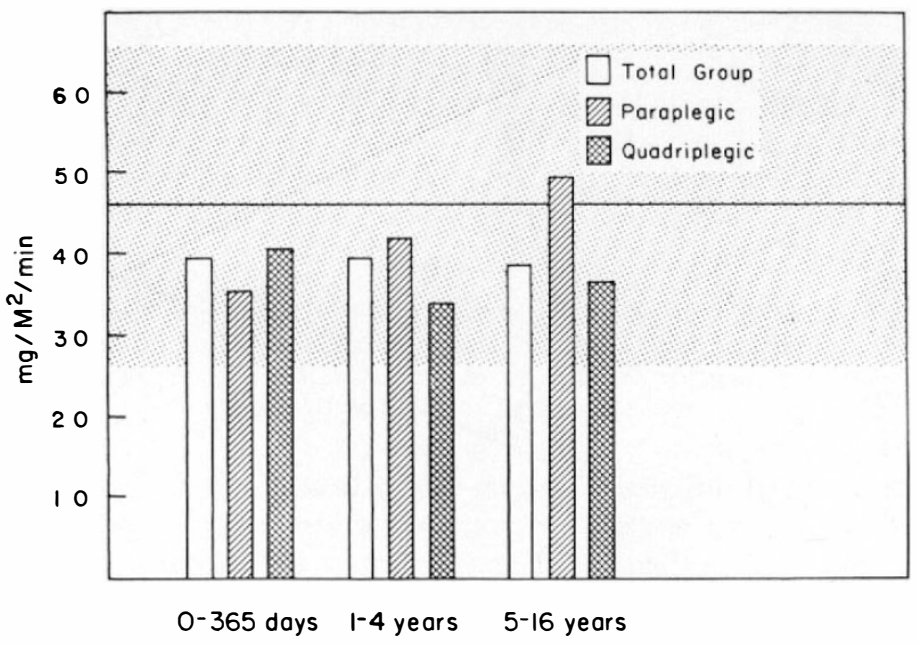

FIG. 2

Mean values for TmPAH in patients with duration of lesion of 0-364 days, one through four years and five through sixteen years. Horizontal line indicates main normal value. Cross hatching indicates two standard deviations above and below normal. 


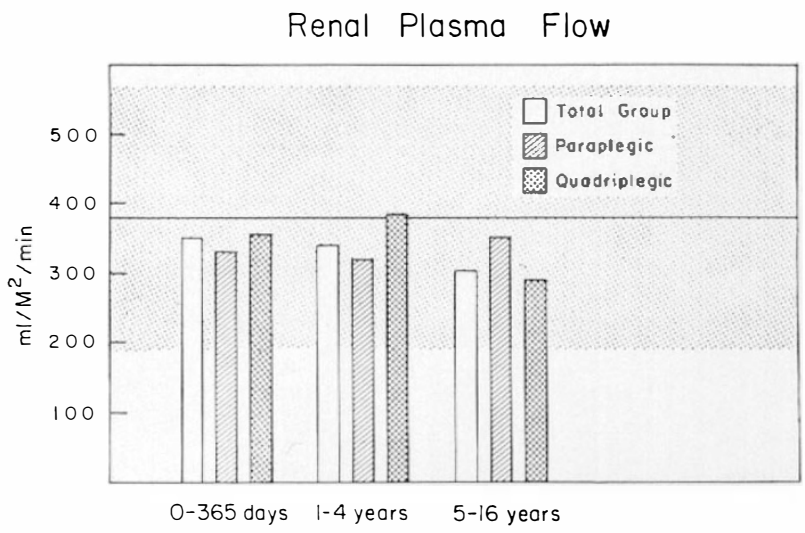

FIG. 3

Mean values for renal plasma flow in patients with duration of lesion of 0-364 days, one through four years and five through sixteen years. Horizontal line indicates main normal value. Cross hatching indicates two standard deviations above and below normal.

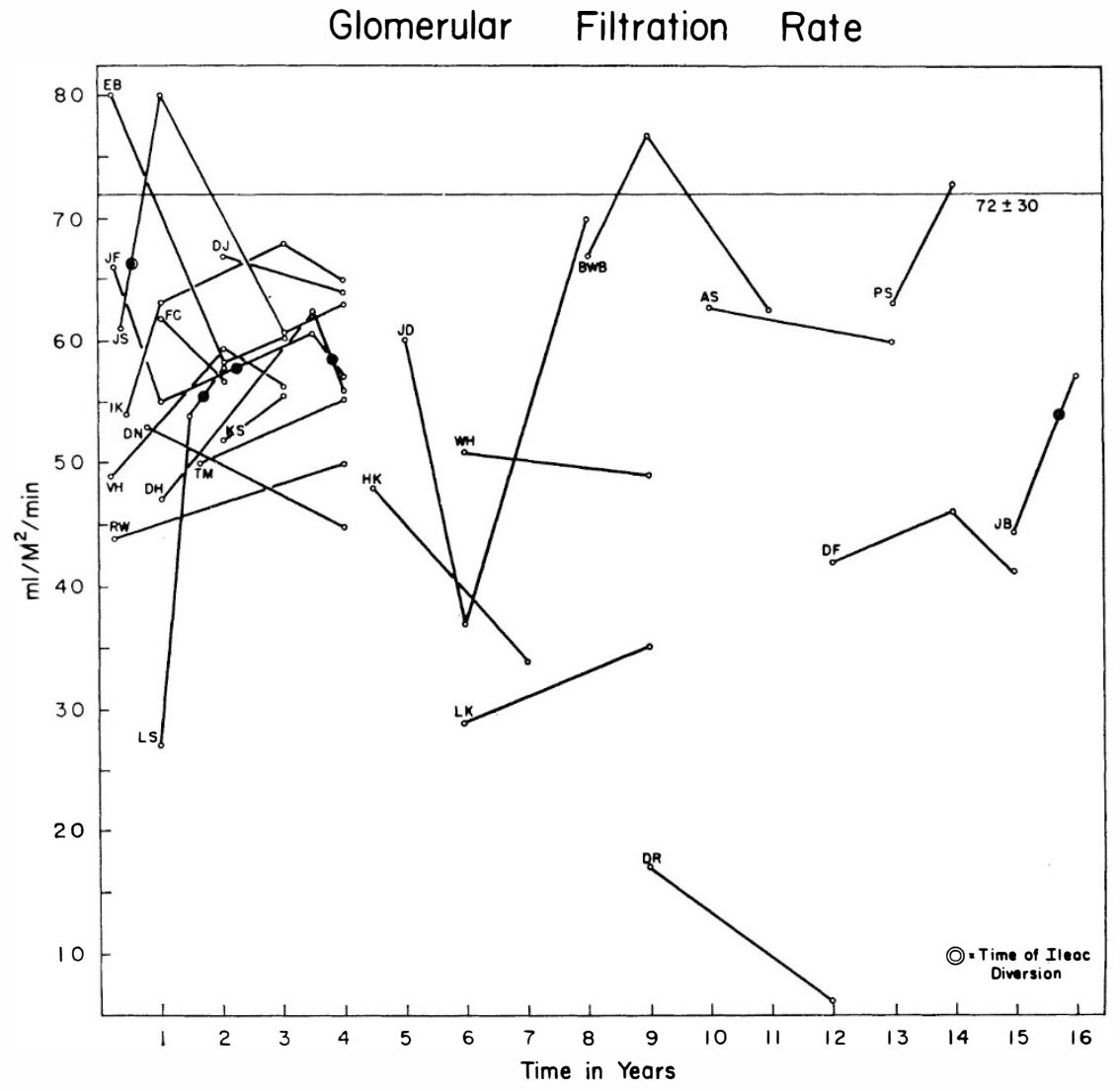

Fig. 4

Change in glomerular filtration rate is represented in twenty patients who have had serial testing. Small circles indicate testing period. Double circle indicates when ileac diversion, if any, was done. Horizontal line shows mean normal value. Mean normal value \pm 2 standard deviations is stated at right of horizontal line. 
Two patients were found to have markedly depressed renal function. These were two young men with incomplete cervical lesions of 9 and 15 years duration. Glomerular and tubular function were depressed in both. Bacteriuria was present in both. The man with the 9-year lesion has bilateral reflux. He uses a Foley catheter for bladder drainage. The patient with the lesion of I 5 years' duration has left reflux and suprapubic drainage.

Two patients show moderate functional depression. In a young woman who had an incomplete cervical lesion of six month duration, glomerula filtration rate

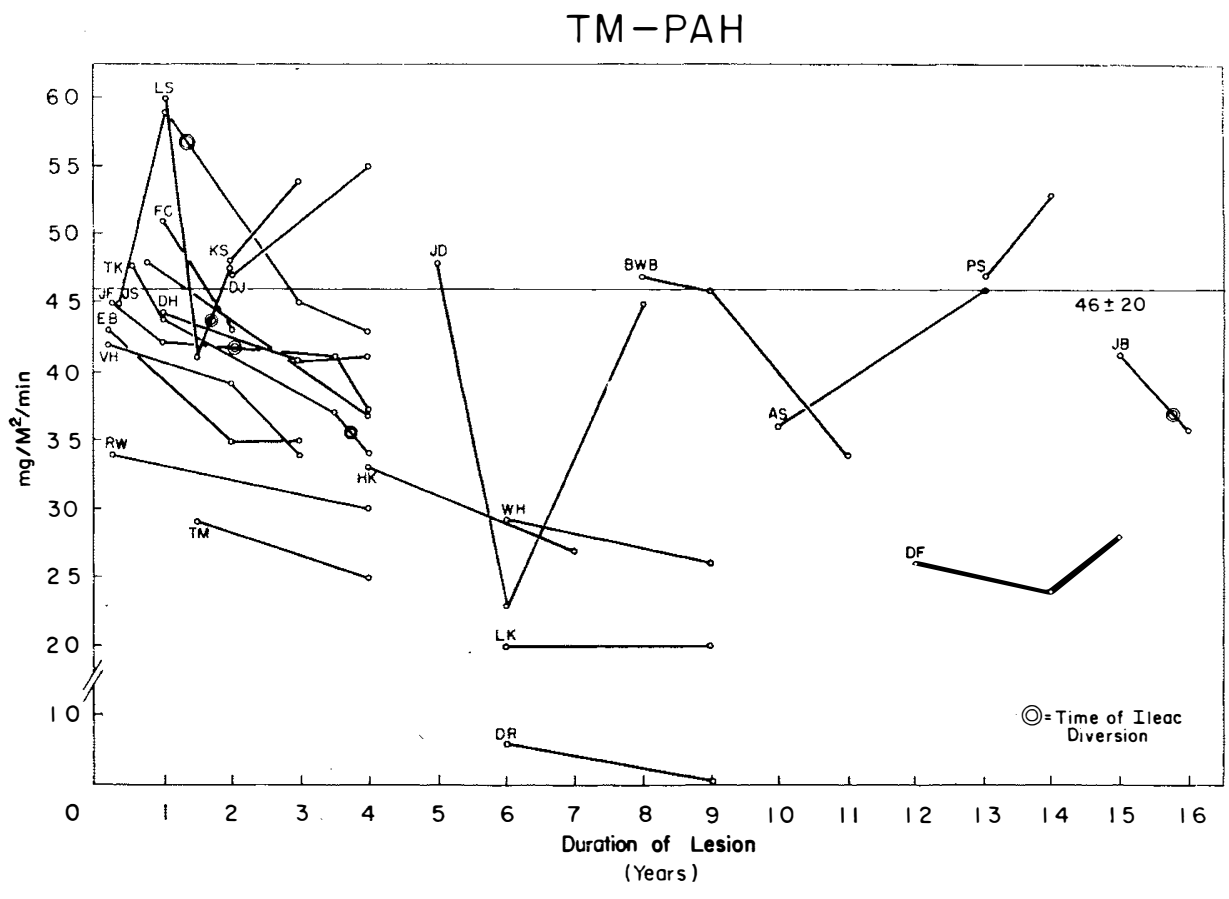

FIG. 5

Change in TmPAH is represented in 20 patients who have had serial testing. Small circle indicates testing period. Double circle indicates when ileac diversion, if any, was done. Horizontal line shows mean normal value. Mean normal value \pm 2 standard deviations is stated at right of horizontal line.

was below normal, TmPAH was in the second deviation from normal. A Foley catheter was used. There was an incomplete left reflux. A young man had a complete cervical lesion of 9 years' duration. TmPAH was below normal and GFR was in the second standard deviation from normal. He utilised condom drainage, had sterile urine and had no reflux. Post voiding X-rays showed considerable residual urine.

\section{SUMMARY}

Studies have been made of glomerular filtration rates, maximal tubular excretory capacities and renal plasma flows in 72 patients with traumatic spinal cord 


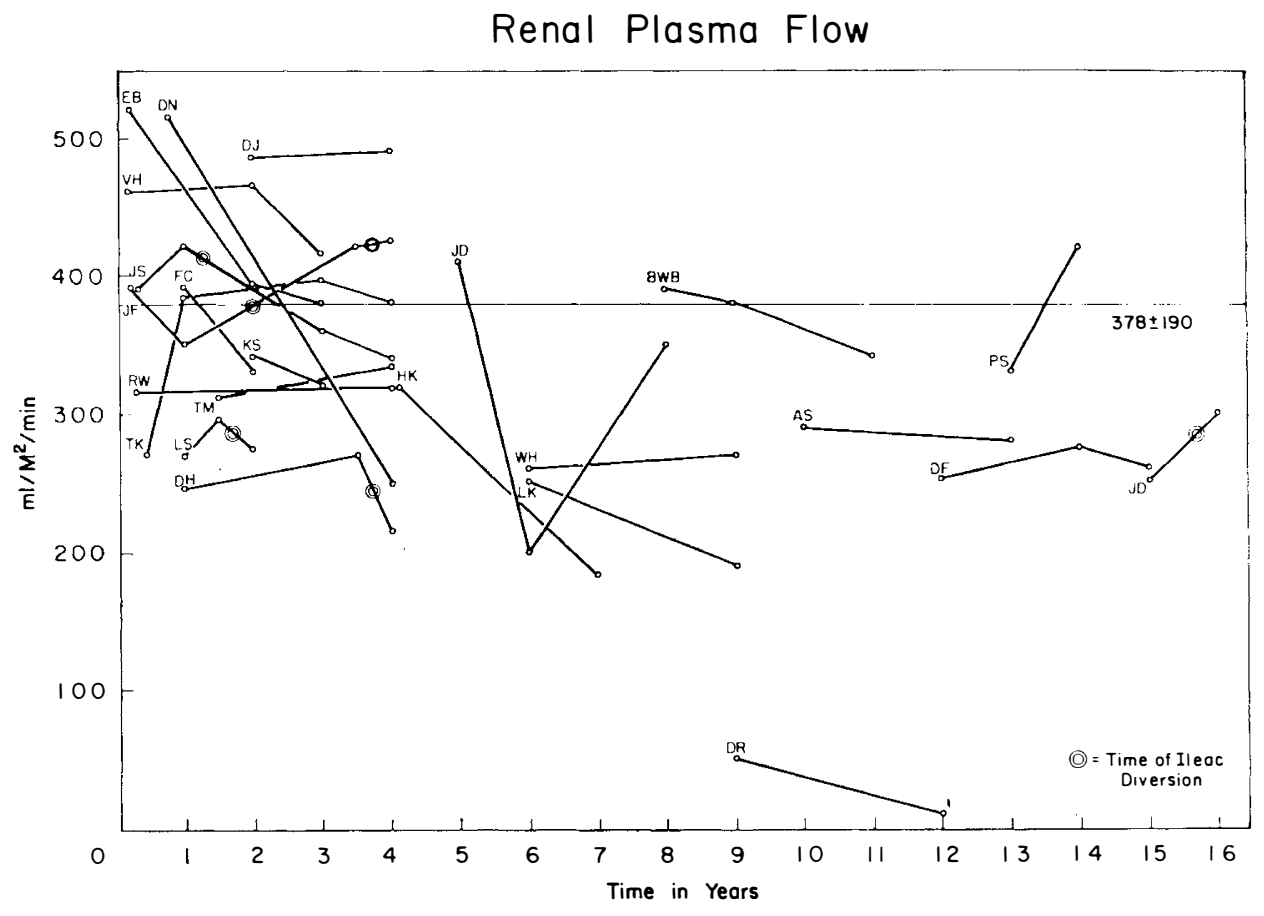

FIG. 6

Change in renal plasma flow is indicated in 20 patients who have had serial testing. Small circles indicate testing period. Double circle indicates testing period. Double circle indicates when ileac diversion, if any, was done. Horizontal line shows mean normal value.

Mean normal value $\pm \mathbf{2}$ standard deviations is stated at right of horizontal line.

injuries. Serial observations of 20 patients have been possible over a period of four years.

Findings strongly suggest that over a period of I6 years, glomerular, tubular and circulatory function of the kidney does not significantly decline in those patients who avoid recurrent infection and recurrent decubiti.

This research was supported in part by Vocational Rehabilitation Administration Research and Training Centre Grant No. 2.

\section{REFERENCES}

Bojesen, E. (1952). Acta med. scand. 142, 275 (Suppl. 266).

Bratton, A. C. \& Marshall, E. K., JR. (1939). F. biol. Chem. 128, 537.

Smith, H. W. (1962). Physiology of the Kidney, p. 62. New York: Oxford University Press.

Price, M., Tobin, J., Reiser, M., Olson, M., Kubicek, W., Kottke, F. \& Boen, J. (I966). Archs phys. Med. 47, 407.

Price, M., Olson, M., BoEN, J. \& Kottke, F. Renal function in patients with spinal cord injuries. Proceedings of I5th Annual Conference on Spinal Cord Injuries (in publication). 